\title{
The Research on College English Education Evaluation System
}

\author{
He Zhijing ${ }^{1}$, Yin Xin ${ }^{2}$ \\ ${ }^{1}$ Department of Preschool Education, Hebei Women's Vocational College, \\ Shijiazhuang 050091, China \\ ${ }^{2}$ Department of Nursing, Hebei Women's Vocational College, \\ Shijiazhuang 050091, China \\ 447304258@qq.com
}

Keywords: College English, Education Evaluation, System

\begin{abstract}
University English education evaluation system reform is an important part of college English teaching reform. The new evaluation system can be defined as: based on constructivist theory, in order to promote learning, the subject participated and organized closely integrated with teaching and various forms of evaluation activities. This study was according to the specific situation of college English teaching and summarized more relevance and practical significant new evaluation system in the college English teaching process.
\end{abstract}

\section{Introduction}

Teaching Evaluation is the correct assessment of the teaching process, including the evaluation of teaching and learning. Wherein the method and the evaluation of student achievement goals are the main teaching evaluation directly affect the students' learning motivation and learning attitude, but also affect the teaching methods and course content. Studies have shown that the proper use of the examination and evaluation of the development of other new means to promote teaching progress; new assessment could implement to nature through teacher training teaching situation, play the role of promoting learning. Under this philosophy influence, the language evaluation in the field of education began to try to explore new evaluation theory and practice [1].

University English education evaluation system reform is an important part of college English teaching reform. The new evaluation can be defined based on the basic theory of constructivism, in order to promote science as the main purpose of teaching the subject by the participation and organization, closely integrated with teaching various forms of evaluation activities. How to build a people-oriented, in order to master the learning content to the principle of the students' basic language skills and the quality of the comprehensive evaluation of the new evaluation system, is foreign language researchers and teachers an urgent problem.

\section{The Construction of College English Education Evaluation System}

Summative evaluation is a teaching phase summative assessment at the end and based on test scores to assess the quality of student learning and teaching, including the end of course examinations and proficiency tests. Summative evaluation methods currently is the main foreign language teaching is both an important way to test students' comprehensive ability to use language, but also an important indicator of teaching effectiveness, school quality. After the 1990s, it began to receive attention formative assessment, teachers use formative assessment effectively adjust all aspects of teaching and students' learning behavior. Discussion formative assessment from the perspective of the exam, can help teachers guide students to learn, adjust their teaching methods and materials.

The construction of learning process evaluation. In the traditional college English teaching evaluation, attention is learning outcomes, as students get answers and other thought processes essential for students to develop something that is often abandoned outside evaluation of vision. So that is not conducive to students a good quality of thinking, and will limit students to experience the 
fun of thinking, thereby inhibiting the students to solve problems of flexibility and creativity. To evaluate students' English learning process mainly from four aspects:

Evaluation of students' participation. In the evaluation of student participation and its focus is on the students to participate in the comprehensiveness, depth, initiative research.

Evaluation of student awareness of cooperation and exchange Evaluation of a student's sense of cooperation and exchange, to consider the following factors: the students not only to learn on their own also be responsible for the crew; to guide teachers' organizations, groups shared their wisdom and thinking; students to complete learning tasks bear individual responsibility ; to improve cooperation and communication skills students learn to cooperate signs, has a good sense of division of labor is also a measure of the standard; Students should be able to explain to each other what they have learned, can help to understand each other and to complete the job; mutual trust between students and to communicate effectively [2] .

Evaluation of student emotions and attitudes. Students in the College English Classroom emotional feelings can be divided into: a sense of fun, a sense, anxiety, boredom. The same students learning English experience is not static, but in a period of time, students learning English emotion reflected relative stability; English learning, emotional experience of students not only have one, but in a certain period there is always a major emotional experience.

Evaluation of use the language ability to think. College English is the language of thinking activity. Evaluation of students' thinking process, not only pay attention to whether students can actively think independently, but to pay attention to them in the learning process shown by the thinking strategies, standards and quality. Students with quality independent thinking, not only to be good at independently ask questions and solve problems, but also to properly evaluate and test their conscious thinking activity, correct mistakes, and constantly improve and enhance the quality of thinking activity; but also good evaluation of others analysis and problem-solving thinking activities.

The construction of classroom evaluation. Classroom assessment is one of the main forms of classroom study, it is a combination of formative assessment teaching approach designed thinking and a series of teaching methods based on. This approach is in the classroom for students continuing evaluation by teachers to understand students' learning situation and the teacher's own teaching situation. Keynote college English classroom assessment is that through effective feedback between teachers and students, to achieve the purpose of improving the teaching quality and student learning quality.

Characteristics of College English Classroom Evaluation. College English classroom assessment has the following characteristics: to improve student-centered learning methods; teacher-led; both teachers and students benefit; look at the issue with a development perspective; concrete, small-scale; rooted in a good classroom teaching practice.

Value and practice performance of classroom assessment. From a practical perspective, the use of classroom assessment to promote quality teaching and learning, the effect is very obvious. Specific features: classroom teacher in the design of appropriate technology assessment, showing remarkable creativity; designing classroom assessment data collected and analyzed with reality; teachers evaluate students' interest in learning, teachers and creating a will Students linked bonds, so that students more conscious and aware of their own status as learners; classroom assessment provided for teachers, on teaching a sensible platform for dialogue among colleagues; teacher as a colleague by the organization seminars, writing academic journals, as well as teaching and learning in the study design is more refined, more sophisticated evaluation of classroom work, access to recognized experts.

Evaluation criteria of university English teaching. Classroom teaching evaluation criteria include: college English classroom teaching evaluation standard guidelines, including the promotion of all-round development of students in order to develop evaluate student teachers, focusing on the evaluation of the development of other content; basic principles of college English classroom teaching evaluation standard including oriented principle, scientific principle, the principle of comprehensiveness and feasibility of principles; teachers should have the basic skills, including the ability to lifelong learning, strong adaptability and resilience, the ability to reflect education, 
competency-based education network resources the ability to activate the creative ability and psychological counseling [3].

The construction of CAI evaluation. In this study, combined with the new evaluation method for college English teaching situation CAI empirical analysis, summed up the process of reform in college English teaching in the new evaluation model has more relevance and practical significance of view. CAI teaching mode provides for the establishment of a new evaluation system for efficient network platform and aids, while traditional evaluation methods cannot meet the needs CAI teaching mode, the new evaluation model has become a necessity. The new evaluation model embodies the concept of student-centered, more comprehensive and objective evaluation of the student's learning process and confirmed the students' learning potential and determine the direction of improvement and development, and help students complete knowledge of the construction of meaning Evaluation.

Practice environmental of CAI assessment mode. English Teaching Reform in the implementation process of the implementation of the hierarchical teaching by grading test targeted at different levels of English proficiency of students to carry out teaching activities. Foreign university students learning environment for all digital multimedia language lab Foreign Language Teaching Experiment Center, the center of the core technology used in ATM network technology. Data is transmitted through time-division multiplexed manner, each user has a virtual real-time, high-speed leased line data transmission, to ensure the smooth voice, to solve the voice digitization process of language delay, fracture and other issues, foreign language teaching to meet the real-time voice professional requirements interaction. Meanwhile, the full realization of this teaching system functions classroom computer network, subject to the effective control of a computer running the teachers to ensure reliable operation of classroom teaching and other functions.

The backwash effect of the CAI new evaluation model. In this study, the students writing peer assessment, rapid reading self-assessment and case study of English Listening Strategies questionnaire. By analyzing the electronic archives of student learning, and student interviews and questionnaires, we feel the new evaluation system on the basis of the existing evaluation methods reflects a variety of advantages to teaching a positive backwash effect. CAI teaching mode has build an interactive learning environment for language learning and to guarantee student exchanges and cooperation, between teachers and other learners. Under the CAI mode, the process of foreign language teaching in the university evaluation, the application process more efficient new evaluation model, the application effect is more prominent, enable students to truly become the subject of evaluation [4].

Technical support for implementation of the new evaluation model. Multimedia network platform technology for the implementation of the new evaluation model provides a reliable technical support. Hardware platform, software platform, the English resource and so has provided a guarantee for the evaluation model of information. Interactive help of multimedia network platform to enable students to give full play to the role of the cognitive subject, breaking the traditional barriers of space evaluation mode, valid for the new assessment process feedback information and provide direct access to technical support. We should further rely on campus network resources, to build a more comprehensive network of language learning environment, achieved by opening all-digital multimedia language laboratory learning network platform to language change, and then build the campus test systems and operations management systems.

\section{The Practice and Application of New Evaluation Models in College English Education}

College English teaching is the teachers and students to participate in the completion of the process. To achieve the goal of teaching, improve teaching standards, teachers need to have a clear understanding of the teaching process and effective monitoring. As one of the means of monitoring learning evaluation is not only an important part of the curriculum, but also an important guarantee to achieve teaching objectives. Evaluation of properly designed, both to help students understand the curriculum focus and their own learning progress, to help them acquire the knowledge and skills learned, but also to give students a sense of accomplishment, and thus stimulate their interest in 
learning. At the same time, the good evaluation methods can help teachers understand the learning situation as much as possible in the various stages of the learning process, the psychological needs and a lot of other related information.

Select evaluation experimental methods. The experiment uses two empirical evaluation methods and humanities. Advantages empirical method is accurate, efficient, rigorous mathematical methods it accurately analyze the resulting data, the evaluation can be an accurate description of the object; at the same time, it is based on objective facts and data to conclude that a strong persuasive. But because it is difficult to evaluate the quantitative methods of development within the object and analyze the reasons for the changes, so easily lead to situations results-light process, but also a certain lack of flexibility. The Humanities evaluation timely and effective solution to the problems in the evaluation process, while concerned about the interpersonal exchange of the evaluation process, and highly relevant, can pay attention to analyze the reasons behind the problem, so they can better play Evaluation Features. However, the subjectivity, to a certain extent, the individual's subjective consciousness containing evaluator, thus affecting its validity. Because of Humanities evaluation method has its unique educational function, often as a primary means of formative evaluation. In teaching evaluation, should give full play to the empirical and humanity strengths depending on the circumstances and be complementary, so that the evaluation has a positive effect.

The overall score approved program of practical evaluation system. Traditional evaluation only concerned about scores, the new evaluation system should reflect the students' emotions, attitudes, values assessment, but if canceled scores and grades, but it is difficult to reflect the evaluation of the selection, distinguishing features that make students lack their own reasonable position and forward The goal. To change a summative test findings and other drawbacks, the unit can open a closed book exam results, a comprehensive practice scores (research work, classroom activities, etc.), evaluation of attendance and the learning process equivalent to $30 \%$, then the end of the period written exam equivalent to $70 \%$ recorded in the overall rating, thereby highlighting the process of evaluation, both reasonable and comparable [5].

\section{Conclusion}

Practice shows that the new evaluation system has many advantages and it has had a positive impact for college English teaching reform. This study attempts to explain the implementation effect and the problems of the new evaluation in college English teaching. This study based on extensive empirical research and the personal practice of teachers and students and it laid the foundation for the establishment of a more scientific workable new college English evaluation system.

\section{References}

[1] L.P.Gao, The English verb, mood and grammatical category probe, J. Foreign Language Teaching. 10 (2015) 18-21.

[2] M.li, The research on English virtual tone grammar, J. Sichuan International University. 3(2009) 61-64.

[3] L.H.Wang, The past grammar from the experience of Philosophy, J. Foreign Language Teaching, 32(2012) 189-190.

[4] J.X.Shen, The syntax of language usage, J, Fujian Western, 4(2007) 39-42.

[5] Y.M. Tian, The English teaching evaluation, J. Foreign Language Teaching and Research, $4(2001)$ 268-275. 